\title{
ENSAIOS
}

Sabrina Eggers ${ }^{l}$

\section{ESTUDO SOBRE O SEGUNDO PÓLO DE DEFESA NACIONAL: CASO DE SANTA MARIA, RS}

\section{THE STUDY OF THE SECOND NATIONAL DEFENSE POLE: CASE OF SANTA MARIA, RS}

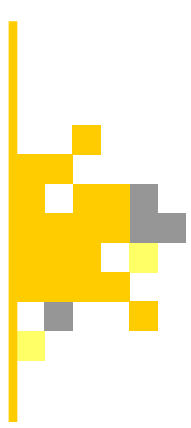

\section{RESUMO:}

A defesa nacional é crucial para a soberania do país. A soberania de um país é o conceito chave das Teorias de Relações Internacionais, sendo necessária e fundamental no Sistema Internacional. Este trabalho tem por objetivo analisar o segundo polo ${ }^{2}$ de defesa nacional, a cidade de Santa Maria, RS. A mesma torna-se essencial e de um significado estratégico para o Brasil, na sua manutenção da soberania.

Palavras-Chave: Defesa Nacional, Segundo Pólo de Defesa, soberania, Santa Maria.

\begin{abstract}
:
National defense is crucial to the country's sovereignty. The sovereignty of a country is the key concept of International Relations Theories, being necessary and fundamental in the International System. This work aims to analyze the second pole of national defense, the city of Santa Maria, RS. It becomes essential and of strategic significance for Brazil in its maintenance of sovereignty.
\end{abstract}

KeYwords: National Defense, Second Defense Pole, Sovereignty, Santa Maria.

\section{INTRODUÇÃO}

O desenvolvimento de uma estratégia e uma forte política de defesa configuram-se como primordiais para estabelecer a soberania e a força de um país contra possíveis ameaças externas. Nenhum país deve deixar de produzir os próprios recursos para defender a sua nação, levando em consideração sua realidade política, econômica e social.

O governo brasileiro estabelece seus objetivos na área da defesa nacional por meio da Política Nacional de Defesa, a PND. É um documento que traz o planejamento das ações de controle da soberania, desenvolvido pelo Ministério da Defesa. É voltado às ameaças externas e estabelece as orientações para o preparo das forças civis e militares em busca da Defesa Nacional. Conforme a PND: "Esta política pressupõe que a defesa do país é inseparável do seu desenvolvimento, fornecendo-lhe o indispensável escudo". Dessa maneira, a Defesa Nacional é crucial para a soberania de um país. A soberania é um conceito base para as Relações internacionais e, dessa forma, a Defesa Nacional deve ser estudada e preservada. A cidade de Santa Maria é considerada o segundo pólo de defesa nacional, sendo assim, é de extrema importância para o Brasil e a manutenção de sua soberania. Este trabalho tem por objetivo geral analisar de que forma a cidade de Santa Maria tornou-se o segundo pólo de defesa nacional e, como objetivo específico, estudar bases militares da cidade.

\footnotetext{
${ }^{1}$ Bacharel em Relações Internacionais (UFSM); Especialista em Geopolítica e Defesa (UFRGS) iD https://orcid.org/0000-0002-8325-9653 Artigo elaborado para a obtenção do referido grau e adaptado para a publicação na revista científica Interação da UFSM.

${ }^{2}$ Entende-se por pólo uma guarnição, segunda cidade com maior efetivo militar.
} 


\section{ORIGEM DE SANTA MARIA}

A cidade de Santa Maria é localizada na região central do Estado do Rio Grande do Sul, e é conhecida por seu grande contingente militar, sendo considerada o Segundo Pólo de Defesa do Brasil. O município possui uma importância estratégico-militar para o país.

Os primeiros registros históricos e geográficos sobre a origem da cidade estão relacionados à delimitação territorial do tratado do Santo Idelfonso, de 1777, o qual estabelecia os limites entre os domínios da Espanha e de Portugal no sul do Brasil. Esse processo de delimitação foi executado pela Comissão Demarcadora de Limites da América Meridional e a partir disso a região de Santa Maria foi uma importante referência geográfica para os trabalhos da Comissão.

Inserida no contexto geopolítico da Bacia do Prata, a cidade de Santa Maria surge como uma referência para a conquista da região sul brasileira pelos portugueses, e também na guarnição de suas fronteiras. Na origem da cidade se estabelece fases de desenvolvimento. A primeira fase está ligada à guarda portuguesa de São Pedro e do acampamento militar da Comissão Demarcadora de Limites. Já na segunda ocorreu uma expansão urbana com o estabelecimento das unidades militares de Santa Maria.

A formação territorial do Rio Grande do Sul teve seu marco com a Colônia do Sacramento, pois foi com ela que ocorreram as mobilizações militares para a defesa dos interesses econômicos na região e que, consequentemente, provocaram o surgimento de povoados aos arredores e formaram acampamentos militares em diferentes cidades do Rio Grande do Sul. Através da exploração econômica do Sul, os portugueses deixaram marcos referenciais no caminho das Missões, dentre eles a cidade de Santa Maria. Referenciais geográficos que acabaram se tornando povoados e mais tarde deram origem às cidades conhecidas.

Conforme Machado (p.43-44):

Através dessa exploração econômica e geográfica pelo Sul, os portugueses dei- xaram como marcos referenciais, no caminho das Missões, alguns elementos, como: os Campos de Vacaria, Santo Antônio da Patrulha, Passo Fundo, Cruz Alta, Santo Ângelo, São Borja, São Martinho da Serra, Santa Maria da Boca do Monte e o rio Jacuí. Referenciais geográficos que se tornaram povoados $e$ mais tarde, deram origem a municípios gaúchos.

A paz temporária entre Portugal e Espanha veio a partir do tratado de Santo Idelfonso, de 1777, o qual seu objetivo era impedir o avanço castelhano, estabelecendo uma faixa ao longo do limite, a qual, supostamente separaria as duas nacionalidades. Em contrapartida ao tratado, o governo português reincorpora o território que atualmente é o Rio Grande do Sul aos seus domínios militares para poder expulsar qualquer invasor. A partir do deste tratado, a cidade de Santa Maria passa a adquirir uma importância estratégica na geopolítica portuguesa. Segundo Machado (p.53):

\footnotetext{
Considerada, desde o período colonial, um referencial geográfico, por causa do caminho para as Missões, Santa Maria adquire uma relevância geoestratégica para os interesses de Portugal e, mais tarde, do Império do Brasil na questão platina, desempenhando a função de consolidação das fronteiras ao sul e também da sua defesa frente aos países vizinhos. Esta característica, cuja origem provém do período colonial, manifestase visivelmente na cidade até os dias atuais, pelo número de estabelecimentos e contingente militar, do exército e da aeronáutica, preparados para a defesa das fronteiras ao sul do país.
}

O papel desempenhado por Santa Maria ocorreu no conflito da Banda Oriental, através de tropas do exército pacificador. A segunda divisão do exército acampou na cidade, instaurando um quartel general na atual Rua do Acampamento, concentrando tropas dos Setes Povos das Missões. Somente no ano de 1810 os militares deixaram o acampamento e, Santa Maria exercendo sua função militar, fornecendo tropas para o exército por- 
tuguês. A partir dessa referência geográfica, a cidade adquire importância geoestratégica no Rio Grande do Sul.

Em 1828, o 28을 Batalhão de Caçadores alemães acamparam em Santa Maria, com finalidade de ingresso na Guerra da Cisplatina. Embora a guerra estivesse próxima ao fim, a chegada do contingente alemão instalado na região, foi um fato decisivo para o desenvolvimento da mesma. Os soldados que estiveram na cidade modernizaram a economia local e também imprimiram um caráter militar-germânico.

\section{3 - A CIDADE DE SANTA MARIA - RS}

Com forte influência militar na região, a cidade de Santa Maria concentra, atualmente, cerca de 17 instituições militares e uma base aérea, juntamente às residências, áreas de lazer e de treinamento militares. As duas forças de defesa, exército e aeronáutica, juntas, constituem um contingente operacional de aproximadamente 5 mil militares. A importância geoestratégica que a cidade adquiriu advém do período do Brasil colonial, referente à região do Prata. Isso contribuiu para que ela se tornasse um dos maiores pólos militares do país, concentrando um significativo efetivo e poderio militar. Conforme o Chefe de Estado Maior da 3a Divisão de Exército em Santa Maria, Coronel Almeida Rosa:

O valor estratégico de Santa Maria foi o fator determinante para que o Império e, posteriormente, a República estabelecessem em torno dessa região tropas de considerável valor, como elemento de dissuasão e condição de garantia da soberania nacional no sul do país. Assim sendo, o município apresenta grande número de unidades militares desde sua origem, tropas essas que, efetivamente, estiveram relacionadas ao processo de formação territorial do Estado.

Pode-se afirmar que o grande número de unidades militares na cidade é um reflexo de seu passado, juntamente à formação do estado do Rio
Grande do Sul, no qual a sua região contribuiu para a questão do Prata, a sua conquista e defesa.

Dessa forma, Santa Maria é, atualmente, considerada uma referência geoestratégica para a segurança do país. A principal fonte de renda do município, hoje em dia, é o comércio, o qual atende militares e suas famílias, juntamente com exército e aeronáutica, prestando serviços, atuando na área de transportes, escolas, hospitais, bancos, restaurantes, entre outros.

Conforme Machado (p.140):

\begin{abstract}
Com isso, Santa Maria constitui-se em um centro polarizador dentro da mesoregião geográfica centro-ocidental do Estado, exercendo forte atração comercial e na prestação de serviços orientados pelo funcionalismo público e pela agropecuária da região.
\end{abstract}

Essa característica é atribuída devido à sua natureza histórica, na qual Santa Maria vinha se envolvendo em antigos conflitos platinos, estabelecendo um grande contingente militar. O contingente militar da cidade está constituído, aproximadamente por 8000 militares da ativa e da reserva, juntamente às suas famílias, representando um grande número de consumidores da atividade local, como na área de transporte, comércio, saúde, educação e serviços. Atualmente a base da economia da cidade de Santa Maria é o comércio e serviços.

\section{1 - BASES MILITARES}

Por possuir o segundo maior contingente militar do Brasil, a cidade de Santa Maria conta com inúmeras instituições de cunho militar. O seu mapa, conta com várias unidades do exército e uma base aérea, a qual abrange uma área do sentido urbano ao rural, do centro às periferias, das regiões norte e sul, leste e oeste.

A Base Aérea de Santa Maria situa-se ao lado da Universidade Federal de Santa Maria, em uma região mais distante da cidade. As áreas de lazer vinculadas ao exército situam-se no chamado Círculo Militar, um clube esportivo e de temporada 
de verão utilizado por sócios militares e também por civis, situado ao norte da cidade, no sopé da serra. Na região central da cidade estão localizadas as bases militares, especificamente na rua Doutor Bozano, as quais servem de moradia dos sargentos do exército. Tem-se também a Vila Militar e o Hotel de Trânsito do Exército, que ocupam as avenidas Borges de Medeiros e Presidente Vargas e são destinadas aos militares e suas famílias.

Os quarteis de Santa Maria estão distribuídos pelos variados bairros da cidade. A chamada 6a Bateria de Artilharia Antiaérea é localizada um pouco mais para o sul, e já o Depósito de Subsistência ao final da rua Marechal Floriano Peixoto e próximo a via férrea da cidade. No centro, estão localizadas as mais antigas unidades do exército, como a 3a DE, e o antigo 70 RI, atual 6a Bda Inf Bld, ambos situados no alto da Avenida Borges de Medeiros. Mais ao oeste, tem-se o quartel do 3 GAC AP, o Regimento Mallet, e também, o Hospital da Guarnição.

Mais para oeste, percebe-se uma área significativa destinada às forças armadas, correspondente ao Parque de Manutenção das viaturas militares, o qual possui grande valor à cidade, devido às suas atribuições. $\mathrm{O}$ mesmo limita-se aos bairros: Caturrita, Juscelino Kubistchek, Nova Santa Marta, Passo da Areia e faz limite com o arroio Cadena, este estando próximo dos quarteis do Mallet e do Paque de Manutenção. Na mesma área, há ainda o Colégio Militar de Santa Maria. À sudoeste da cidade, com uma área de aproximadamente, 5000 hectares, aloja-se o Campo de Instrução, o qual se estende do Sul à oeste. Tem por finalidade o treinamento militar e simulações de guerras. Nessa mesma região estão localizados os quarteis do 29 $\mathrm{BIB}$, 40 B LOG, 60 Esq. C MEC e mais recentemente, o 10 RCC e o C I BLD, transferidos do Rio de Janeiro. No início do século XX, ele abrigou as instalações do antigo Parque de Aviação Militar.

A Terceira Divisão do Exército (3a DE) tem como área de responsabilidade mais da metade do território do Rio Grande do Sul, e a cidade de Santa Maria como sede. Estão subordinadas à 3 a $\mathrm{DE}$ a 6a Brigada de Infantaria Blindada e o Campo de Instrução de Santa Maria. Segundo Machado:
A sede do comando da 3a ${ }^{\mathrm{D} E}$, como é chamada pelos militares, está localizada em Santa Maria, mas a sua área de influência abrange quase todo o Rio Grande do Sul, 46,88\% do território gaúcho. Apresenta ao todo um efetivo de aproximadamente 16000 militares distribuídos em 15 guarnições e 44 organizações militares no Estado compreendendo os municípios de Santa Maria, Cachoeira do Sul, Rosário do Sul, Quaraí, Uruguaiana, Alegrete, Itaqui, Santiago, São Borja, Cruz Alta, São Luís Gonzaga, ljuí, Santo Ângelo, Passo Fundo e Santa Rosa, distribuídos ao longo da fronteira com a Argentina e ao centro do estado.

O Campo de Instrução de Santa Maria está diretamente ligado à 3 a $\mathrm{DE}$, e sua área diz respeito à mais ou menos 5000 hectares de utilização militar e de agropecuária, estende-se da área dos quarteis do Boi Morto até o arroio Sarandi. Já a 6a Brigada de Infantaria Blindada comenda organizações militares sediadas nas cidades de Santa Maria, Rosário do Sul e Cachoeira do Sul. Dentre elas:

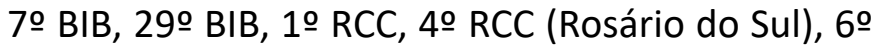
ESQ C M, CIBLD, 3 GAC AP, 6a BIAAAé, 12 B E C BLD (Cachoeira do Sul), 40 B LOG, 3a CIA COM, CIA Cmdo, 26 PEL PE.

\section{CONSIDERAÇÕES FINAIS}

A cidade de Santa Maria, no Rio Grande do Sul é considerada o Segundo Pólo de Defesa, contando atualmente com o maior contingente militar, atrás apenas da cidade do Rio de Janeiro. É de extrema importância para a Defesa Nacional e a manutenção da soberania brasileira.

Sua importância estratégico-militar foi herdada de seu passado colonial, datado do contexto da Bacia do Prata, o qual a cidade surge como um importante ponto de referência para a conquista do território do Sul pelos portugueses e também para a defesa de suas fronteiras. A sua primeira fase diz respeito aos estabelecimentos militares, através da antiga Comissão Demarcadora de Limites, anteriores ao ano de 1801 . A sua segunda fase 
está relacionada a expansão urbana com o estabelecimento das unidades militares.

Foi a partir do Tratado de Santo Idelfonso, de 1777 que Santa Maria passou a adquirir uma importância na geopolítica portuguesa, pois encontrava-se entre os dois reinos. Também teve papel fundamental para a questão platina, a qual desempenhou função de consolidação das fronteiras do Sul e também serviu de defesa para o território dos vizinhos. Essa característica que provém do período colonial ainda pode ser vista nos dias de hoje, devido ao grande número de estabelecimentos militares, entre exército e aeronáutica, com a finalidade de defesa do território.

Dessa forma, pode-se concluir que o que tonou a cidade de Santa Maria o segundo pólo de defesa nacional foi a sua herança histórica deixada por portugueses e espanhóis durante o Brasil colonial, pois foi ela que serviu de acampamento militar e de caráter geoestratégico, devido à sua localização central e proximidade com os antigos reinos.

\section{REFERÊNCIAS}

ARQUIVO HISTÓRICO MUNICIPAL. Acervo Histórico e Bibliográfico sobre Santa Maria. Prefeitura Municipal de Santa Maria,2006.
BEBER,C.C. Santa Maria 200 anos-História da economia do município. Santa Maria:Palloti,1998.

BELÉM ,J. História do município de Santa Maria. Santa Maria: UFSM, 1989.

.História do município de Santa Maria (1797/1933).3aed.Santa Maria:Ed. Da UFSM,2000.

BELTRÃO,R. Cronologia histórica de Santa Maria1787-1930 e do extinto município de São Martinho. Santa Maria:IHGRS,1979.

Sinopse histórica de Santa Maria,In: Guia Geral do município. PACHECO, J.A.(org.). Santa Maria,1953.

FLORES, M. História do Rio Grande do Sul:Série História Gaúcha. Porto Alegre,v.3: Martins Livreiro,1986.

FREITAS, M.S. da. Importância militar de Santa Maria In : Revista Comemorativa do Centenário de Santa Maria. Porto Alegre: Officinas Gráphicas da Livraria do Globo, 1914.

GUILHERMINO, C. História do Rio Grande do Sul. 2.ed. Porto Alegre: Globo,1980

MACHADO, Márcia Kaipers. A presença do Exército e da Aeronáutica na organização espacial de Santa Maria - RS. Dissertação de Mestrado em Geografia, 2008. 